\title{
Research on Problems and Countermeasures of Implementing ERP in SMEs*
}

\author{
Shaoqin $\mathrm{Lu}$ \\ School of Economics and Business Management \\ Changzhou College of Information Technology \\ Changzhou, China
}

\begin{abstract}
With the advent of the information age, SMEs urgently need to use information technology to improve their management level. ERP system is through the information technology management platform to standardize the company's business processes, achieve enterprise's information integration and sharing, improve business processing speed and service levels, and enhance the company's management efficiency and competitiveness. Through the analysis of the ERP implementation process for SMEs, the corresponding solutions and countermeasures are put forward for the problems and difficulties faced by the enterprises in implementing ERP.
\end{abstract}

Keywords-SMEs; implementation; ERP; countermeasures

\section{INTRODUCTION}

Enterprise Resource Planning (referred to as ERP) system is a software system that integrates modern management ideas and management methods based on information technology, and it provides business solutions for businesses. At the same time, it is not only a set of management information systems, but also an integrated management platform for enterprise business. In terms of management concepts, it incorporates a variety of modern management ideas and technologies, integrating Just-in-time, lean production, business process reengineering, agile manufacturing, supply chain management, and customer relationship management. In terms of enterprise resources management, the ERP system integrates physical resources such as traditional "human", "finance" and "material", and also includes intangible resources such as knowledge management, business intelligence, and ecommerce. Now, enterprise informatization has become an essential means for enterprises to improve efficiency and competitiveness. The successful implementation of ERP has become the most critical content and mark in enterprise informatization, and ERP systems have also been agreed and accepted by more and more companies.

With the globalization of economy, the rapid development of small and medium-sized enterprises (referred to as SMEs) has made great contributions to the economic development of

*Jiangsu University of Philosophy and Social Science Outstanding Innovation Cultivating Team Construction Project (No 2017ZSTD035) phased research results.

Changzhou College of Information Technology, Manufacturing and Internet Fusion Innovation Development Research Base (CXPT201702R) phased research results. the entire society. The development level of SMEs marks the overall economic development level and potential of a country. However, due to the external business environment and the constraints of the company's own conditions, the survival and development of SMEs are faced with various difficulties. Therefore, it is urgently necessary to change their own business management models, continue to carry out management innovation, and vigorously promote the enterprise's informatization construction and informatization management. Among them, the implementation of ERP systems in SMEs can greatly reduce the company's operating costs, increase the efficiency of corporate capital turnover, improve inventory turnover, improve production capacity, and help companies to win more economic and social benefits. Therefore, it is a great theoretical value and practical significance to study the problems and countermeasures of implementing ERP in SMEs. [1]

\section{PROCESS AND STEPS OF IMPLEMENTING ERP IN SMES}

The value of ERP has been widely recognized by companies. More and more companies have chosen ERP as an effective tool for comprehensive improvement of management level and competitiveness. The implementation of ERP is the process by which companies effectively use ERP software systems. The process of implementing ERP for SMEs mainly includes the contents of four parts: project planning, blueprint design, system implementation and acceptance delivery.

\section{A. Project Planning}

In order to ensure the successful implementation of ERP, before starting the specific implementation work, the company must do a good job in project planning, and set the direction and route for the implementation process of ERP. First, in the implementation of the ERP requirements survey, needs to clarify the reasons, effect and scope of the implementation of ERP, determine the necessity of the implementation of ERP and the objectives to be achieved. Secondly, through the feasibility analysis, the technical feasibility and economic feasibility of implementing ERP in enterprises are determined, including the hardware equipment, network technology, software technology, application technology and technical personnel needed to the implementation of ERP, and the impacts of investment cost and economic benefits to the corporate management methods will be considered too, these 
will be used as the basis for ERP system investment decisions. Finally, also need to select the appropriate ERP software vendor to ensure that ERP can be successfully implemented. [2]

\section{B. Blueprint Design}

In the blueprint design stage, according to the results of the company's needs analysis, the company's business solutions are designed. The main tasks include ERP standard function training, prototype building, business solution design, static data preparation, personalized function development, and business process design. The implementation party of ERP must evaluate and optimize the business process on the basis of prototype testing, rethink and redesign the operation mode of the existing business of the company, change those unreasonable processes, focus on the goals and benefits, and establish a smooth business process channel for SMEs.

\section{System Implementation}

In the system implementation stage, ERP follows the business process model in the blueprint design to establish a system online environment, user rights allocation, data preparation, system integration testing, user training, simulation drills, system switching, etc., so using the ERP system instead of the original business management model can achieve the goals of informatization management.

\section{Acceptance Delivery}

After formal switching of ERP system is completed, ERP shall be formally accepted for delivery. The tasks of this stage mainly include: operation support, monthly settlement, continuous optimization diagnosis, project summary. The implementation of ERP is a long-term journey. The emphasis on ERP systems by senior corporate leaders is a key factor in the success of ERP systems. Enterprises must continue to improve business process after implementing ERP, so that the management level and economic benefits of enterprises can be continuously improved.

\section{PROBLEMS AND DIFFICULTIES OF IMPLEMENTING ERP IN SMES}

According to the statistics of the American Institute of Production and Inventory Control, in the aspect of economic efficiency, enterprises can reduce inventory level by $20 \%$ to $35 \%$, improve inventory turnover rate by $50 \%$, reduce delivery delay by $80 \%$, and shorten purchase lead time by $50 \%$, production capacity increased by $10 \%$ to $15 \%$. However, in many SMEs, the successful implementation of ERP does not exceed $50 \%$, and $60 \%$ of them are using a single-function financial processing software, inventory management software and procurement management software, only about $10 \%$ of companies each individual management software is integrated and information is shared, and less than $1 \%$ of the enterprise's comprehensive informatization management is implemented. Although implementing ERP can improve the management level and competitiveness of SMEs, due to the limitations of its own management level and capabilities, SMEs are faced with many problems and difficulties in implementing ERP, and the risk of failure to implement ERP is high. [3]

\section{A. Managers Have Misunderstandings about ERP}

Some SMEs managers have two extreme phenomena in their understanding of ERP. The first is that ERP can solve all problems in the business process, the expectation of ERP is too high, and the ERP system is over-reliance, while ignoring the essence of ERP is only to provide advanced management ideas and management tools to help effective corporate resources configuration and information sharing. Some SMEs don't combine their own actual needs, greed for large-scale ERP functions, and blindly invested in IT projects that led to the failure of implementing ERP. Second, some SMEs managers believe that the implementation of ERP is useless, ERP is only computer software, the scale of the company is small, the economic business is not complicated, and the business processing of the enterprise can be completed manually, and there is no need to implement ERP. The managers of this group of companies do not pay enough attention to the implementation of ERP, they do not fully and correctly understand the value of ERP, and they do not realize that the implementation of ERP changes to management methods and management concepts will inevitably lead to the failure of ERP projects.

\section{B. The Funds are Limited and the Level of Enterprise Informatization is Low}

Implementing ERP is a complex system project. In terms of scope, most departments of the enterprise are involved. At the same time, the basic conditions for informatization of SMEs are relatively high. There are numerous network devices, servers, and clients on the hardware, and requires integration between the database management system, application software, and other management software. Due to the long span of implementation of ERP, the cost of purchasing software, implementing and maintaining is relatively high, while SMEs are generally small in scale and difficult to raise funds, and cannot provide sufficient support for ERP projects in funds. According to statistics, $90 \%$ of the SMEs that failed to implement ERP were caused by the time and cost exceeding expectations.

\section{Lack of ERP Expertise}

The requirement of implementing ERP for enterprises is "three-point technology, seven-point management, and twelve talents", In the process of implementing ERP, the human factor is the most important. First, implementing ERP requires the support of corporate management. All employees actively participate in and cooperate with the implementation of ERP. At the same time, they also require ERP suppliers to have a strong implementation team and experienced implementation personnel in order to ensure the smooth implementation of ERP work. However, SMEs have limited capital strength and it is difficult to get the appropriate implementation team to help companies implement ERP. Secondly, the demand of ERP for talents is complex. It is necessary to master information technology and understand the advanced management methods and management ideas, so that they can carry out business operations and maintenance of ERP systems. These experts are in short supply and urgently needed for SMEs. 


\section{Backwards Management Foundation}

Many SMEs' management concepts are backward, there is no sound corporate management system, employees have unclear job responsibilities, there is a phenomenon of long lead, and lack of premise and basis for the implementation of ERP. First, there are problems of the basic data accuracy in implementing ERP system. The basic data includes static data and dynamic data. The static data refers to the beginning data of the enterprise and is the basis for the normal operation of the ERP. The dynamic data refers to the data generated during the operation of the enterprise and often expressed as a business document. If the basic data is inaccurate, ERP will generate a lot of useless "spam." Because of the limitations of the quality and level of the employees, the source of basic data is not unique, the format is not standardized, and the integrity and accuracy of the data cannot be controlled, which directly affects the accuracy of ERP system data. Second, there are problems in the business process reengineering. Business process reengineering refers to rethinking and reengineering the business process of an enterprise in order to maximize its effectiveness in the use of corporate resources and to improve its product quality, reduce costs, improve service levels and speed of response. In addition, due to the influence of traditional habits, corporate managers and grass-roots employees are unwilling to accept new business processes and are still operating according to the old methods, which also lead to difficulty in business process reengineering.

\section{COUNTERMEASURES FOR IMPLEMENTING ERP IN SMES}

\section{A. Establish Goals for Implementing ERP and Product Selection}

First, companies should choose the right type of ERP product and choose the right supplier according to their actual needs. The implementation of ERP is long-term system engineering, and must be well planned and selected. The selection method of good ERP products is to combine the actual requirements of the enterprise with the standard logic of ERP, makes ERP products have the idea of data integration and the concept of cross-department collaboration, so that you can achieve the actual needs and specific goals of business management. Companies can use the ERP software four-area technical function matrix proposed by the Gartner Group for product selection. The technical function matrix model is shown in "Fig. 1" below. The four areas in the figure indicate remain area, reinforce area, rebuild area and review area. Among them, area III and area IV indicate that the software is lacking in function and technology and needs to be greatly improved. Area I indicates that the software is advanced in function and technology. It is the leader of ERP software products on the market. Area II represents the choice of advanced software technology, but its function still needs improvement. These two areas can be used as the key consideration for enterprises to choose ERP software products. In terms of supplier selection, generally consider suppliers with strong technology, rich experience, and successful cases of similar companies.

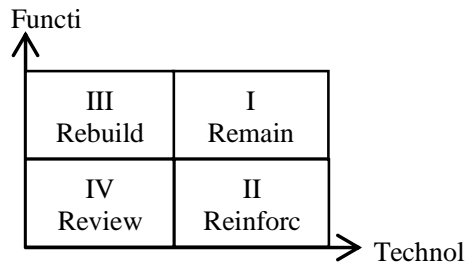

Fig. 1. The technical function matrix model.

Second, the scope and objectives of ERP system implementation should be clear. It is necessary to systematically plan the time, cost, personnel and risks in the ERP project. Clear implementation objectives and practical implementation methods are the guarantee for the success of the ERP project. The goal of implementing ERP should be combined with the actual business operations of the company and be consistent with the development goals of the company. Based on the analysis of the bottlenecks and influencing factors of the development of the enterprise, the overall objectives and phased objectives of the implementation project should be formulated, such as the accuracy of inventory data, finegrained management of materials, and coordination between supply chain and production. Due to the constraints of time, funds, manpower, and resources, SMEs are usually not able to implement ERP in all their businesses at the same time, and it is impossible to implement all the functions in ERP at the same time. In the implementation progress, step-by-step implementation and gradual adoption are needed. The advancing method not only guarantees the financial support needed for the implementation of ERP, but also steadily advances the informationization process of the company. Such as, the company implements the informationization of warehouse and material management first, and then gradually to the supply chain management, production management, financial management, until the enterprise's information as a whole. [4]

\section{B. Strengthen the Implementation Team Building and Conduct All Staff Training}

The understanding and awareness of ERP by the senior management of a company and the degree of support in the implementation process directly affect the success or failure of implementing ERP. Prior to the implementation of ERP, all employees of the company must be educated and trained in awareness. For the training of senior managers, they should be made aware of the role, value, and purpose of ERP. Clear that the implementation of ERP is an essential element of enterprise development. Only through the implementation of ERP, enterprises can achieve improvement in their management level and core competitiveness, so that the company must strive to obtain their strong support from senior managers for the implementation of ERP. In addition, in the implementation process of ERP, there will inevitably be conflicts in business management methods and management concepts. The senior managers of the enterprise must give sufficient support to the ERP, eliminate difficulties and resistance factors, and coordinate the conflict between the enterprise departments and personnel, efforts to promote the implementation of ERP. [5] 
The training of ERP project managers and key users should enable the internal ERP implementation personnel to understand both management and information technology, and to have good communication and organization and coordination capabilities. The project leader generally selects middle managers from inside the company to understand the actual situation of the company, but also has rich working experience and extensive human relations, which is conducive to the smooth progress of the entire ERP project. The key users are the backbones of various departments. Through the learning and training of ERP operation manuals and normative processes, they can help the general users of the company to quickly promote the full implementation of ERP projects. After the project planning and ERP product selection, it is necessary to form an implementation team for the ERP project. The implementation team of the ERP project must have a long-term and stable workforce. They need to have a solid theoretical basis for ERP, but also have rich experience in ERP implementation. They are generally composed of three parties: ERP software providers, supervision consulting companies, and internal staff. ERP software provider personnel have indepth research on ERP software products and experience with successful implementation of many similar companies. Being familiar with the process of implementing ERP can help companies reduce implementation time, cost and risk. The personnel of the supervision consulting company understand the implementation of ERP evaluation indicators and evaluation system, can monitor the quality of the entire ERP implementation process, and provide reasonable advice to the specific business management methods. The internal employees of the company have a deep understanding of the enterprise, are familiar with the processing methods and processes of the specific business, and can combine the ERP software products with the actual work of the enterprise. [6]

\section{Strengthen the Collection and Organization of Basic Eenterprise Data}

Any enterprise has a large amount of basic data and business data. Standardized, timely and correct standardized data is the basic guarantee for the good operation of the enterprise ERP system. Practice has proved that inaccurate data is one of the important reasons for the failure of many SMEs to implement ERP. Therefore, in ensuring the integrity and accuracy of various data, SMEs must do a good job of training grass-roots employees in advance, clarify the division of labor between the various departments, and be responsible for the data collected by each department. In the data preparation process, guidance is given by the implementation consultant to ensure that the basic data is timely, effective, complete and accurate. The basic data of ERP system operation mainly includes: material documents, bills of materials, process routes, work centers, inventory records, and lead time. Among them, the accuracy rate of bills of materials and process routes must be above $98 \%$, and the accuracy of inventory record data should be above $95 \%$. [7]

\section{Pay Attention to Business Process Reengineering and Continuous Improvement System}

Business process reengineering embodies the process as the center, to improve the efficiency and management level of all businesses in the entire process, and to improve the overall service level and response speed of the enterprise. The Business process reengineering establishes the standardization of business processes, emphasizes the rational allocation of resources in business processes, achieves the purpose of information transfer and sharing through the effective use of resources, and finally removes inappropriate links and establishes a reasonable business process flow. The company's management content and objects from business management to process management. [8]

ERP provides advanced enterprise management methods and management tools, realizes the integration and sharing of enterprise information and the standardization of business processes, enables enterprises to use resources more effectively, improves the management level of enterprises, and provides the continuous improvement prerequisites and foundation for companies. Through the standardized management platform of the ERP system, enterprises can discover shortcomings and deficiencies in strategic planning, personnel, technology, quality management and product development, so as to continuously improve these existing problems and continuously enhance the management level and competitiveness of the company.

\section{CONCLUSION}

SMEs are an important part of the national economy. To use information technology to improve the management level and work efficiency, we must rely on the advanced management concepts and management methods of the ERP system. The implementation of ERP is a complex project, and SMEs will encounter many problems and difficulties in the process of implementing ERP. Enterprises need to analyze the objectives and characteristics of implementing ERP, and make efforts in technology, personnel, processes and data. Effective measures to ensure the successful implementation of the ERP system to achieve an overall improvement in the level of service, economic efficiency and competitiveness of the enterprise.

\section{ACKNOWLEDGMENT}

The author acknowledges the valuable comments and suggestions of Editors, conference participants at the 3rd International Conference on Contemporary, Education, Social Science and Humanities (ICCESSH 2018).

\section{REFERENCES}

[1] Zhou Rui. Difficulties and Countermeasures of ERP Implementation in Small and Medium-sized Enterprises[J]. Business Era, 2012(28):88-89.

[2] Chen Xuejun. Analysis of the implementation of ERP in small and medium-sized enterprises [J]. Market Modernization, 2007 (02): 81-82.

[3] CHEN Ren-ren, WU Wei-bao, WANG Chun-yu. Bottlenecks and Countermeasures of SMEs Based on ERP Implementation [J]. Journal of Huaihai Institute of Technology (Social Sciences Edition), 2011, 9(01):77-80

[4] Justyna Patalas-Maliszewska. Assessing the Impact of ERP Implementation in the small Enterprises[J]. Foundations of Management,2012,4(2). 
[5] Justyna Patalas-Maliszewska. Assessing the Impact of Erp Implementation in the small Enterprises[J]. Foundations of Management,2012,4(2).

[6] Yi Zeng,Yi Heng Li. Design and Implementation of ERP System for Small and Medium Sized Enterprises[J]. Applied Mechanics and Materials,2014,3629(686).

[7] Xia Fan. Status and Resolution of ERP Implementation in Small and Medium-sized Enterprises [J]. Economic Research Guide, 2014(32):1820.

[8] Liu Baojian, Wu Chunxu. The characteristics of SMEs and the key issues of ERP implementation [J]. Modern Information, 2006 (02): 167$168+171$. 